\title{
Effects of Fusarium toxin-contaminated wheat and feed intake level on the biotransformation and carry-over of deoxynivalenol in dairy cows
}

K. Seeling ${ }^{a} *$, S. Dänicke ${ }^{a}$, H. Valenta ${ }^{a}$, H. P. Van Egmond ${ }^{b}$, R. C. Schothorst ${ }^{b}$, A. A. Jekel ${ }^{b}$, P. Lebzien ${ }^{a}$, M. Schollenberger ${ }^{c}$, E. Razzazi-Fazeli ${ }^{d}$ and G. Flachowsky ${ }^{a}$

*Correspondence: Email: karen.seeling@fal.de.

The assistance of the co-workers at the Institute of Animal Nutrition and the Experimental Station of the Federal Agricultural Research Centre in Braunschweig, Germany, in performing the experiment and analyses, as well as the support of this study by the H. Wilhelm Schaumann Foundation (Hamburg, Germany), is gratefully acknowledged.

${ }^{a}$ Federal Agricultural Research Centre (FAL), Institute of Animal Nutrition, Bundesallee 50, Braunschweig, D-38116, Germany; ${ }^{b}$ Laboratory for Food and Residue Analyses (ARO), National Institute for Public Health and the Environment (RIVM), EU Community Reference Laboratory for Residues (CRL), PO Box 1, NL3720 BA Bilthoven, The Netherlands; ' Institute of Animal Nutrition, Hohenheim University, Emil-Wolff-Str. 10, Stuttgart, D-70599, Germany; ${ }^{d}$ Department of Veterinary Public Health and Food Sciences/Institute of Nutrition, University of Veterinary Medicine, Veterinarplatz 1, Vienna, A-1210, Austria.

(Received 7 March 2005; revised 23 March 2005; accepted 18 April 2005)

\begin{abstract}
An experiment was carried out to examine the effects of feeding Fusarium toxin-contaminated wheat $(8.21 \mathrm{mg}$ deoxynivalenol (DON) and $0.09 \mathrm{mg}$ zearalenone (ZON) per kg dry matter) at different feed intake levels on the biotransformation and carry-over of DON in dairy cows. For this purpose, 14 ruminal and duodenal fistulated dairy cows were fed a diet containing $60 \%$ concentrate with a wheat portion of 55\% (Fusarium toxin-contaminated wheat (mycotoxin period) or control wheat (control period)) and the ration was completed with maize- and grass silage (50:50) on a dry matter basis. Daily DON intakes ranged from 16.6 to $75.6 \mathrm{mg}$ in the mycotoxin period at dry matter intakes of $5.6-20.5 \mathrm{~kg}$. DON was almost completely biotransformed to de-epoxy DON (94-99\%) independent of the DON/feed intake, and the flow of DON and deepoxy DON at the duodenum related to DON intake ranged from 12 to $77 \%$ when the Fusarium toxin-contaminated wheat was fed. In the serum samples, de-epoxy DON was detected in the range of $4-28 \mathrm{ngml}^{-1}$ in the mycotoxin period, while concentrations of DON were all below the detection limit. The daily excretion of DON and de-epoxy DON in the milk of cows fed the contaminated wheat varied between 1 and $10 \mu \mathrm{g}$ and between 14 and $104 \mu \mathrm{g}$, respectively. The total carryover rates as the ratio between the daily excretion of DON and de-epoxy DON into milk and DON intake were in the ranges of 0.0001-0.0002 and 0.00040.0024 , respectively. Total carry-over rates of DON as DON and de-epoxy DON into the milk increased significantly with increasing milk yield. In the urine samples, de-epoxy DON was the predominant substance as compared with DON with a portion of the total DON plus de-epoxy DON concentration to $96 \%$ when the Fusarium toxin-contaminated wheat was fed, whereas the total residues of DON plus de-epoxy DON in faeces ranged between 2 and $18 \%$ of DON intake in the mycotoxin period. The degree of glucuronidation of de-epoxy DON was found to be approximately $100 \%$ in serum. From 33 to $80 \%$ of DON and from 73 to $92 \%$ of de-epoxy DON, and from 21 to $92 \%$ of DON and from 86 to $100 \%$ of de-
\end{abstract}


Food Additives and Contaminants, Vol. 23, No. 10, October 2006, pp. 1008-1020

epoxy DON were glucuronidated in the milk and urine, respectively. It is concluded that DON is very rapidly biotransformed to de-epoxy DON in the rumen and only negligible amounts of DON and de-epoxy DON were transmitted into the milk within the range of 5.6-20.5 $\mathrm{kgday}^{-1}$ dry matter intake and milk yields (fat corrected milk) between 10 and $42 \mathrm{kgday}^{-1}$.

Keywords: Deoxynivalenol, Fusarium, ruminants, level of feed intake, milk, carry-over.

\section{Introduction}

Deoxynivalenol (DON) is one of the most frequently recognized mycotoxins in Europe produced by several Fusarium species on a variety of cereal grains (Bottalico and Perrone 2002). In animal livestock, ingestion of DON can cause numerous adverse toxicological responses associated with reduced performance and immune function (Rotter and Prelusky 1996). In contrast to pigs, which react most sensitively to DON, ruminants appear to be relatively tolerant, which is attributed to the metabolization of the toxin by microbes in the rumen. Several in vitro studies with bovine rumen fluid have demonstrated that DON is biotransformed extensively to the less toxic compound de-epoxy DON (King et al. 1984; Swanson et al. 1987; He et al. 1992). Consequently, the diversion of cereal batches suspected to be contaminated with DON to ruminants is a useful means of utilizing grain that is unsuitable for humans or monogastric farm animals. However, in combination with higher DON concentrations in cereals and roughage during so-called Fusarium years (Oldenburg et al. 2000), the influence of DON on the health and performance of ruminants should not be underestimated. However, little research has been published on the effects of DON on ruminants. Most of the reports were given as field or case studies and experiments under controlled conditions were only performed with small numbers of animals using either purified DON or naturally contaminated feedstuffs (for reviews, see Höltershinken et al. 1996; Whitlow and Hagler 1999; Bauer 2000; Dänicke et al. 2000; Seeling and Dänicke 2005). Thus, the described effects are quite variable between the different studies and it is difficult to draw conclusions for the practical feeding. Furthermore, high-producing dairy cattle in early lactation also appear more sensitive to DON than low-producing dairy cattle (Whitlow and Hagler 1999). However, no studies are available considering factors other than dosage and duration of toxin exposure, which could cause these differences in susceptibility. Additionally, the information about the carry-over of DON and deepoxy DON into the milk of dairy cows feeding practically relevant concentrations are still rare. While no transmission of DON or de-epoxy DON to milk was observed in a study by Charmley et al. (1993), trace amounts of DON and deepoxy DON could be detected by Prelusky et al. (1984) and Cote et al. (1986).

Possibly, the feed intake (passage rate) as indicator for the feed retention in the rumen could alter the ruminal metabolization of DON. A rapid passage rate as an effect of increased feed intake may limit the available time for a metabolization of DON to de-epoxy DON in the rumen. Due to a modified ratio of DON to de-epoxy DON at the duodenum, the toxicity as well as the carry-over of these substances in the milk could be altered. Therefore, the aim of the present study was to examine the effect of varying levels of feed intake using Fusarium toxin-contaminated or non-contaminated wheat on biotransformation and carryover of DON by dairy cows. The paper is part of a comprehensive study where non-contaminated control wheat and Fusarium toxin-contaminated wheat were fed to ruminants at different feed intake levels. In further papers the influence on ruminal fermentation and milk composition as well as the biotransformation of the mycotoxin ZON were described (Seeling et al. 2005, 2006). 


\section{Material and methods}

\section{Treatments, experimental design and animals}

The experimental design and procedures were described previously (Seeling et al. $2005,2006)$. In brief, 14 dairy cows of the 'German Friesian breed' equipped with permanent ruminal and duodenal cannulas were selected for this experiment. The cows had a mean live weight of $626 \pm 71 \mathrm{~kg}$. The animals were in different stages of lactation: Cows 4-14 and 5-14 lactated in the mycotoxin period and in the control period, respectively, whereas the rest did not lactate. They were tethered using neck straps, housed in a stanchion stable system equipped with individual feedbunks and had free access to water. All cows were fed a diet containing $60 \%$ concentrate and $40 \%$ maize and grass silage (50:50) on a dry matter basis (Table I). The only cereal component of the concentrate was either $55 \%$ uncontaminated control wheat (control period) or 55\% Fusarium toxincontaminated wheat (mycotoxin period). Further components of the concentrate were $25 \%$ soy bean meal, $16 \%$ dried sugar beet pulp, $2 \%$ soy oil and $2 \%$ mineral feed. The composition of the dietary ration was constant for all animals. Only the daily amounts were adjusted individually according to the current performance so that total dry matter intakes of the cows ranged from 5.6 to $20.5 \mathrm{~kg}$. Each cow was fed both the uncontaminated control wheat and the Fusarium-contaminated wheat in two subsequent periods. The concentrate was offered at 05.00, 08.00, 15.00 and 18.00 hours in equal-sized meals. Silage was given twice daily in equal portions at 08.00 and 15.00 hours. Cows were milked at 05.00 and 15.00 hours, and milk yields were recorded at each milking. Weights of the cows were recorded before and after the experimental periods.

Table I. Composition and mycotoxin concentrations of the concentrates and silage.

\section{Concentrate $^{1}$}

\section{Contaminated Control silage silage}

${ }^{1} 55 \%$ (Fusarium-contaminated) wheat, $25 \%$ soybean meal, $16 \%$ dried sugar beet pulp, $2 \%$ soybean oil and $2 \%$ mineral feed per $\mathrm{kg}$ mineral feed: calcium, $175 \mathrm{~g}$; sodium, $100 \mathrm{~g}$; potassium, $50 \mathrm{~g}$; magnesium, $30 \mathrm{~g}$; iron, $1.5 \mathrm{~g}$; manganese, 2g; zinc, 6g; copper, 1.2g; iodine, 30mg; cobalt, 20mg; selenium, 40mg; vitamin A $1000000 \mathrm{IU}$; vitamin $\mathrm{D}_{3}$ 100000IU; vitamin $\mathrm{E}$, 2000IU.

n.a., Not analysed.

\begin{tabular}{|c|c|c|c|c|c|}
\hline Dry matter & $\left(\mathrm{gkg}^{-1}\right)$ & 877 & 885 & 395 & 314 \\
\hline \multicolumn{6}{|l|}{ Nutrients } \\
\hline Crude protein & $\begin{array}{l}\left(\mathrm{gkg}^{-1} \mathrm{dry}\right. \\
\text { matter) }\end{array}$ & 208 & 210 & 76 & 137 \\
\hline $\begin{array}{c}\text { Neutral } \\
\text { detergent fibre }\end{array}$ & $\begin{array}{l}\left(\mathrm{gkg}^{-1} \mathrm{dry}\right. \\
\text { matter) }\end{array}$ & 222 & 226 & 404 & 543 \\
\hline \multicolumn{6}{|l|}{ Mycotoxins: } \\
\hline Deoxynivalenol & $\begin{array}{l}\text { (mgkg }{ }^{-1} \mathrm{dry} \\
\text { matter) }\end{array}$ & 5.2 & 0.1 & 0.6 & $\begin{array}{l}\text { less than } \\
\text { the } \\
\text { detection } \\
\text { limit }\end{array}$ \\
\hline Zearalenone & $\begin{array}{l}\left(\mu \mathrm{gkg}^{-1} \mathrm{dry}\right. \\
\text { matter) }\end{array}$ & 59.4 & 21.7 & 62.4 & 2.0 \\
\hline
\end{tabular}


Food Additives and Contaminants, Vol. 23, No. 10, October 2006, pp. 1008-1020

\section{Measurement and sample collection}

Each experimental period lasted for 4 weeks. Following an adaptation period of 3 weeks to the diets, duodenal samples were collected during the last week in order to estimate the duodenal flow using chromium oxide $\left(\mathrm{Cr}_{2} \mathrm{O}_{3}\right)$ as a marker (Rohr et al. 1984). The marker was given in four boluses into the rumen. Marker administration started 10 days before the duodenal sampling period. Spot samples of duodenal chyme were taken at $2 \mathrm{~h}$ intervals from Monday to Friday yielding a total of 60 samples for each cow. The whole procedure followed the principles as described by Rohr et al. (1979). Blood samples $(25 \mathrm{ml})$ were drawn from each cow in each treatment 1 day in the third week at 10.00 hours. Serum was separated by centrifugation at $2000 \mathrm{~g}$ for $20 \mathrm{~min}$ at $15^{\circ} \mathrm{C} 2 \mathrm{~h}$ after sampling and was kept at $-20^{\circ} \mathrm{C}$ until analysis. Milk sampling from each lactating cow took place through six consecutive milkings in the third week of each period. The samples were pooled based on the weight of milk produced at the morning and evening milking and frozen at $-20^{\circ} \mathrm{C}$, then freeze-dried and stored at $-20^{\circ} \mathrm{C}$ until further analysis. Faecal samples from the rectum as well as spontaneous urine samples were collected in the last week of each experimental period. Faeces and urine were immediately frozen at $-20^{\circ} \mathrm{C}$ after sampling. Representative samples of the concentrates, silage and feed refusals, if they occurred, were collected daily and pooled over the 5 day duodenal sampling trial. For proximate analyses, these samples were dried at $60^{\circ} \mathrm{C}$ and ground to pass though a $1 \mathrm{~mm}$ screen.

\section{Analysis}

Analyses of crude nutrients of feedstuffs were done on dry samples according to the methods of the Verband Deutscher Landwirtschaftlicher Untersuchungs- und Forschungsanstalten (VDLUFA; Bassler, 1976). After the determination of dry matter, duodenal digesta and faeces were freeze-dried and ground to pass though a $1 \mathrm{~mm}$ sieve. Aliquots of the duodenal digesta from each day were pooled according to daily dry matter flow calculated from the $\mathrm{Cr}_{2} \mathrm{O}_{3}$ concentration. Chromium concentration in duodenal digesta and faeces was determined by atomic spectrophotometry according to Williams et al. (1962).

DON in feedstuffs was determined by high-performance liquid chromatography (HPLC) with diode array detection (DAD) after extraction by acetonitrile-water $(83: 16, v / v)$ and clean-up with an immuno-affinity columns (IAC; DONtest HPLC columns, VICAM, Watertown, USA) according to a modified VDLUFA method as described by Valenta et al. (2002). The detection limit was $0.03 \mathrm{mgkg}^{-1}$. The mean recovery rate for feedstuffs was $74 \%$. ZON in feedstuffs was analysed by HPLC after incubation with $2 \cup \beta$-glucosidase (EC 3.2.1.21; No. G-0395, Sigma, Taufkirchen, Germany) according to Ueberschär (1999). The mean recovery rate was $86 \%$. The detection limit was $1 \mathrm{ngg}^{-1}$. Determination of the trichothecenes nivalenol (NIV), scirpentriol, T2-tetraol, fusarenon-X (FUS-X), monoacetoxyscirpenol (MAS), 15-acetyldeoxynivalenol (15-AcDON), 3acetyldeoxynivalenol (3-AcDON), T2-triol, neosolaniol (NEO), diacetoxyscirpenol (DAS), HT-2 toxin (HT2) and T-2 toxin (T2) - was carried out according to a gas chromatography-mass spectrometry (GC-MS) method as described by Schollenberger et al. (2005).

Freeze-dried duodenal digesta and faeces were analysed for DON and deepoxy DON by HPLC-DAD after incubation with $\beta$-glucuronidase, extraction with acetonitrile-water and clean-up by immuno-affinity columns (IAC; DONtest HPLC columns, VICAM) according to Valenta et al. (2003). Serum and urine samples were analysed for DON and de-epoxy DON by HPLC-DAD after incubation with $\beta$ glucuronidase, extraction with a ChemElut ${ }^{\circ}$ cartridge (Varian, Darmstadt, Germany) by ethyl acetate and clean-up with IAC following an HPLC method by Valenta et al. (2003). In contrast to the described method by Valenta et al., incubation with $\beta$-glucuronidase was modified. Acetate buffer, $\mathrm{pH} 5.5$, was added 
to the faeces and urine samples and phosphate buffer, $\mathrm{pH} 6.8$, was added to the digesta and serum samples. After addition of $\beta$-glucuronidase (type $\mathrm{H}-2$, minimum of $100000 \mathrm{Uml}^{-1}$, sulfatase to $7500 \mathrm{Uml}^{-1}$; Sigma-Aldrich, Taufkirchen, Germany), the mixture was incubated overnight at $37^{\circ} \mathrm{C}$. The detection limits for both toxins were approximately $0.02 \mathrm{mg} \mathrm{kg}^{-1}$ (freeze-dried faeces and digesta) and $4 \mathrm{ngml}^{-1}$ (serum) and $10 \mathrm{ngml}^{-1}$ (urine). The recoveries for DON and de-epoxy DON were determined to be 83 and $92 \%$ (duodenal chyme), 92 and $86 \%$ (faeces), 85 and $97 \%$ (serum), and 88 and $88 \%$ (urine), respectively. To confirm the results in serum, four serum samples were incubated, extracted and purified as described above and analysed by HPLC-mass spectrometry (HPLC-MS) according to Razzazi-Fazeli et al. (2003).

Six contaminated serum samples (cows 4, 6, 8, 10, 12 and 14) and six contaminated urine samples (cows $3-5,9,10,14$ ) of cows fed the contaminated wheat were parallelly investigated with and without enzymatic ( $\beta$-glucuronidase) digestion in order to estimate the degree of glucuronidation of DON and de-epoxy DON in serum and urine.

Freeze-dried milk samples were analysed for DON and de-epoxy DON at first without incubation with $\beta$-glucuronidase by a GC-MS method after extraction by water/ethanol (90/10), cleaning up by means of ChemElut $\circledast$ (Varian) and Mycosep $\AA$ columns according to Schothorst et al. (2005). Trimetylsilyl (TMS) ether was used for derivatization and residues were dissolved in iso-octan. Beside DON and de-epoxy DON, the trichothecenes FUS-X, NIV, 3-AcDON, 15-AcDON, DAS, NEO, HT2 and T2 in the milk samples were determined with the same GCMS method. The detection limits for DON, FUS-X, NIV, 3-AcDON, 15-AcDON, DAS, NEO, HT2 and T2 were $0.1,0.16,0.25,0.22,0.18,0.30,0.33,0.22$ and $0.16 \mathrm{ug} \mathrm{kg}^{-1}$. The recovery rates were determined to be $91,96,44,104,97,104$, 109,106 and $111 \%$. The samples were further analysed by HPLC-ultraviolet light (UV) after incubation with $\beta$-glucuronidase, extraction with acetonitrile-water and clean-up by immuno-affinity columns (DONprep, r-biopharm) according to the procedure described above for freeze-dried faeces with slight modifications after detecting de-epoxy DON predominately as glucuronide conjugate in the serum. The recovery rates for DON and de-epoxy DON were determined to be 72 and $89 \%$, respectively. The detection limits were $0.5 \mathrm{\mu g} \mathrm{kg}^{-1}$. All milk samples of cows fed the contaminated wheat were parallelly investigated without enzymatic ( $\beta$ glucuronidase) digestion in order to establish the degree of glucuronidation of DON and de-epoxy DON using the HPLC-UV method. To confirm the results in the milk, the milk samples of all cows fed the contaminated wheat were again analysed by the GC-MS method described above for milk samples with enzymatic

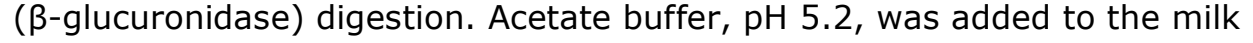
samples. After addition of $\beta$-glucuronidase (Helix pomatia juice from BioSepra; activities $>100000 \mathrm{FUml}^{-1}$ ), the mixture was incubated overnight at $37^{\circ} \mathrm{C}$.

The results of mycotoxin analysis were not corrected for recovery.

\section{Calculations and statistics}

The dry matter flow of the duodenal chyme and the dry matter amount of the faeces were calculated by dividing the amount of chromium $(\mathrm{Cr})$ dosed by the concentration of $\mathrm{Cr}$ of the duodenal digesta and faeces, respectively. Concentrations of DON and de-epoxy DON in duodenal digesta and faeces were calculated by multiplying mycotoxin concentration in duodenal digesta and faeces (on a dry matter basis) with the respective dry matter flow/dry matter amount.

Two carry-over rates into milk were calculated as follows: 
Total carry-over rate into milk $=\frac{\text { daily excretion of DON and/or de-epoxy DON in milk }(\mu \mathrm{g} / \mathrm{day})}{\text { daily DON intake }(\mu \mathrm{gg} / \mathrm{day})}$

Duodenal carry-over rate into milk $=\frac{\text { daily excretion of DON and/or de-epoxy DON in milk ( } \mu \mathrm{g} / \text { day })}{\text { daily DON and/or de-epoxy DON flow at the duodenum }(\mu \mathrm{g} / \mathrm{day})}$

Fat corrected milk (FCM) was calculated as follows:

$\mathrm{FCM}\left(\mathrm{kg} \mathrm{day}^{-1}\right)=((\%$ milk fat $\times 0.15)+0.4)$

$\times$ kg milk yield.

Where applicable, dose-response relationships were evaluated by simple linear regression analysis. All statistics were carried out with the Statistica for the Windows $^{\mathrm{TM}}$ operating system (StatSoft 1994).

\section{Results}

\section{Wheat and diets}

The contents of crude nutrients and amino acids as well as the contents of analysed Fusarium toxins for control and Fusarium-contaminated wheat are summarized in Table II. Only slight differences in crude nutrients could be detected between control and contaminated wheat. The Fusarium toxincontaminated wheat contained on average $8 \mathrm{mg}$ DON and $0.09 \mathrm{mg} \mathrm{ZON} \mathrm{kg} \mathrm{kg}^{-1} \mathrm{dry}$ matter, while $0.25 \mathrm{mg}$ DON and $0.05 \mathrm{mg} \mathrm{ZON} \mathrm{kg}^{-1}$ dry matter were detected in the control wheat. Maize silage, which was used as roughage both in the control and in the toxin rations, also contained low levels of both toxins. In comparison with the control wheat, slightly higher concentrations of 15-acDON, 3-acDON, scirpentriol and HT2 were detected in the Fusarium-contaminated wheat.

Table II. Analyses of selected ingredients and Fusarium toxins in Fusariumcontaminated and control wheat.

\section{Control}

Contaminated wheat wheat

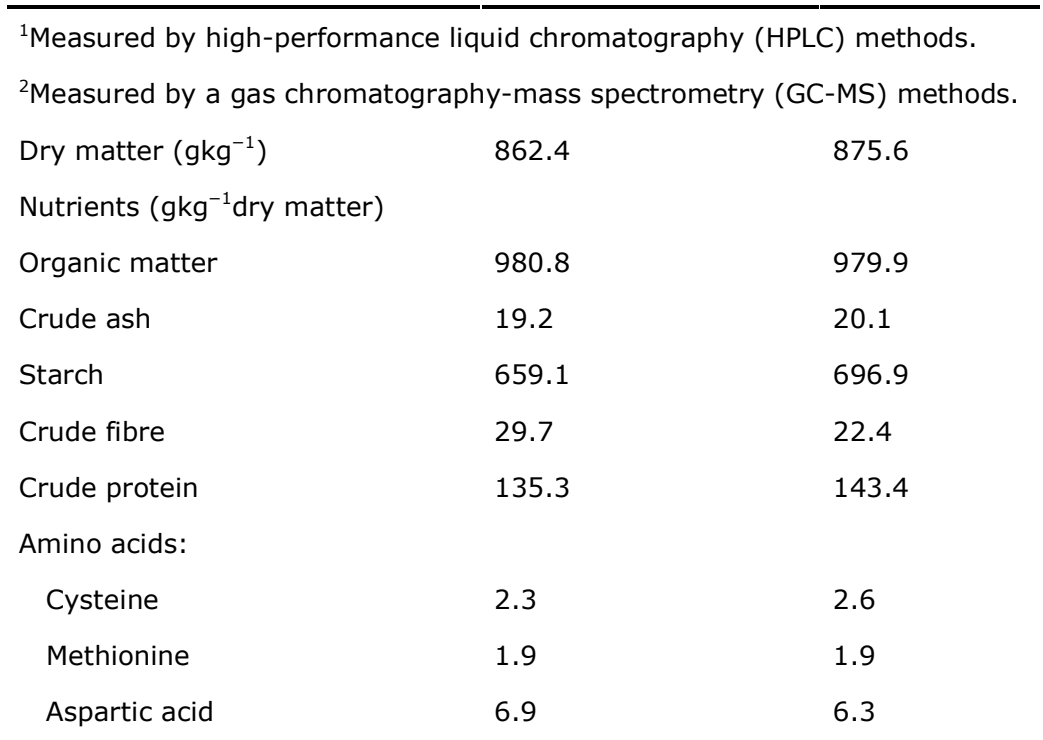




\begin{tabular}{|c|c|c|}
\hline Threonine & 3.3 & 3.4 \\
\hline Serine & 4.9 & 5.7 \\
\hline Glutamic acid & 21.0 & 23.3 \\
\hline Proline & 9.4 & 11.4 \\
\hline Glycine & 4.5 & 4.9 \\
\hline Alanine & 4.3 & 4.4 \\
\hline Valine & 4.7 & 5.0 \\
\hline Isoleucine & 3.8 & 4.1 \\
\hline Leucine & 7.0 & 7.9 \\
\hline Tyrosine & 1.0 & 2.0 \\
\hline Phenylalanine & 5.0 & 5.8 \\
\hline Histidine & 2.9 & 3.1 \\
\hline Lysine & 4.5 & 4.4 \\
\hline Arginine & 5.4 & 5.8 \\
\hline \multicolumn{3}{|c|}{ Mycotoxins ( $\mu \mathrm{gkg}^{-1} \mathrm{dry}$ matter): } \\
\hline Deoxynivalenol $^{1}$ & 8210 & 250 \\
\hline Zearalenone $^{1}$ & 91 & 51 \\
\hline Nivalenol $^{2}$ & 46 & 40 \\
\hline Scirpentriol $^{2}$ & 23 & $<8$ \\
\hline $\mathrm{T}^{2}$-tetraol ${ }^{2}$ & $<7$ & $<7$ \\
\hline Fusarenon- $X^{2}$ & $<19$ & $<19$ \\
\hline Monoacetoxyscirpenol $^{2}$ & $<3$ & $<3$ \\
\hline 15 -Acetyldeoxynivalenol ${ }^{2}$ & 116 & 11 \\
\hline 3-Acetyldeoxynivalenol ${ }^{2}$ & 46 & 11 \\
\hline T2-triol ${ }^{2}$ & $<5$ & $<5$ \\
\hline Neosolaniol $^{2}$ & $<6$ & $<6$ \\
\hline Diacetoxyscirpenol $^{2}$ & $<14$ & $<14$ \\
\hline HT-2 toxin ${ }^{2}$ & 12 & $<3$ \\
\hline T-2 toxin ${ }^{2}$ & $<4$ & $<4$ \\
\hline
\end{tabular}

\section{Mycotoxin flow at the duodenum}

The daily flow of the sum of DON and de-epoxy DON at the duodenum ranged between 2.1 and $35.6 \mathrm{mg}$ after feeding the Fusarium toxin-contaminated wheat and between 0.4 and $4.4 \mathrm{mg}$ after feeding the control wheat (Table III). The predominant substance was de-epoxy DON with a daily flow at the duodenum of $2.1-35.1 \mathrm{mg}$ and of $0.4-4.0 \mathrm{mg}$ in the mycotoxin and control period, respectively, whereas the daily flow of DON varied from 0.04 to $2.2 \mathrm{mg}$ as well as from 0.01 to $1.3 \mathrm{mg}$. The flow of DON and de-epoxy DON at the duodenum relative to the DON intake varied between 12 and $77 \%$ when the Fusarium-contaminated wheat was fed and between 32 and $153 \%$ in the control period. Thereby, the portion of DON and de-epoxy DON of the total DON and de-epoxy DON flow were between 1 and $6 \%$ as well as between 94 and $99 \%$ in the mycotoxin period (Figure 1) and 
between 3 and $35 \%$ as well as between 65 and $97 \%$ in the control period, respectively.

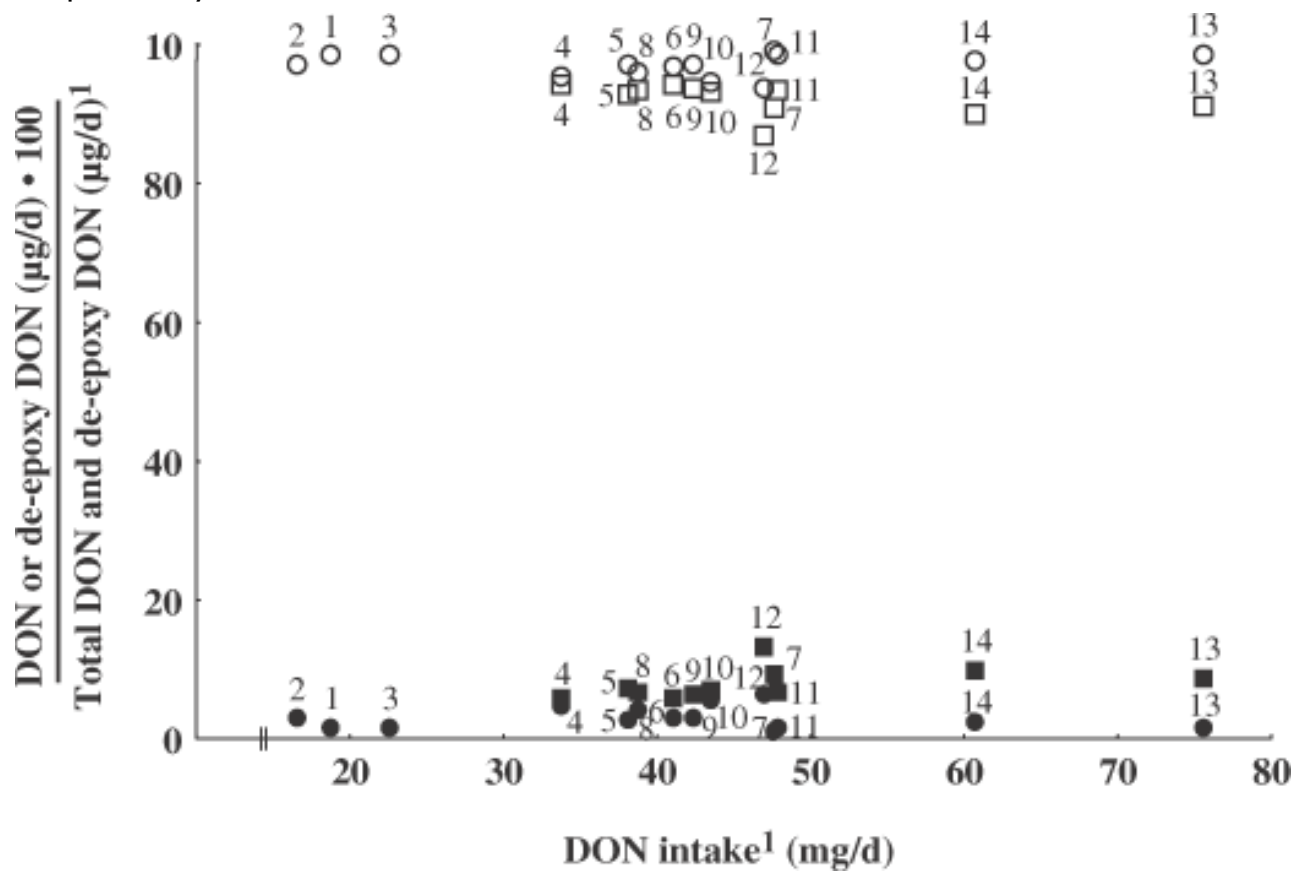

Figure 1. Relationship between deoxynivalenol (DON) intake $\left(\mathrm{mgday}^{-1}\right)$ and the percentage of DON and de-epoxy DON of the total DON plus de-epoxy DON flow at the duodenum as well as the percentage of DON and de-epoxy DON of the total DON plus de-epoxy DON amount in the milk of dairy cows in the mycotoxin period. Metabolite profile of $\bullet, \mathrm{DON}$; and $\hat{\mathrm{x}}$, de-epoxy DON, at the duodenum. Metabolite profile of $\square$, DON; and $\square$, de-epoxy DON, in the milk. Numbers over the symbols denote the individual cows. ${ }^{1}$ Measured by a high-performance liquid chromatography (HPLC) method.

Table III. Dry matter intake, deoxynivalenol (DON) intake, milk yield, daily flow of DON, and de-epoxy DON and DON plus de-epoxy DON flow as a percentage of DON intake at the duodenum of individual lactating cows in the mycotoxin period.

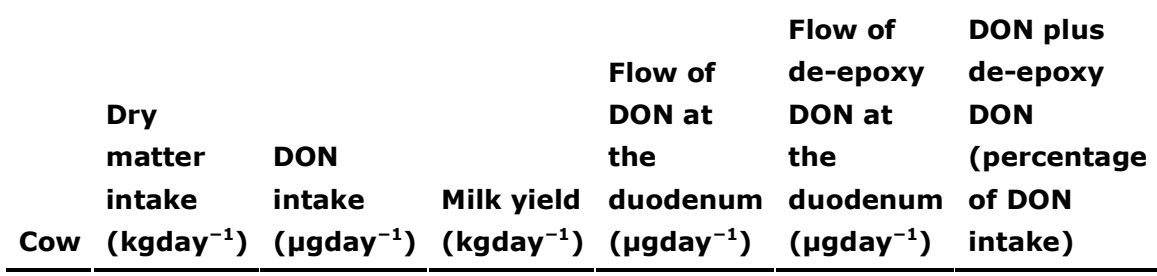

*Cows did not lactate.

$\begin{array}{lllllll}1 & 5.6 & 18800 & -* & 35 & 2104 & 12 \\ 2 & 5.6 & 16570 & -* & 108 & 3650 & 23 \\ 3 & 6.0 & 22620 & -* & 66 & 4059 & 18 \\ 4 & 8.9 & 33840 & 9.6 & 225 & 4698 & 15 \\ 5 & 11.4 & 38090 & 17.8 & 352 & 12170 & 33 \\ 6 & 12.3 & 41040 & 15.4 & 185 & 5745 & 15\end{array}$


Food Additives and Contaminants, Vol. 23, No. 10, October 2006, pp. 1008-1020

\begin{tabular}{rrlllll}
7 & 12.6 & 47580 & 18.0 & 163 & 16539 & 35 \\
8 & 13.1 & 38780 & 19.7 & 526 & 12065 & 36 \\
9 & 15.3 & 42430 & 32.7 & 831 & 27659 & 67 \\
10 & 16.5 & 43510 & 29.1 & 1804 & 31505 & 77 \\
11 & 16.2 & 47900 & 23.7 & 362 & 24342 & 51 \\
12 & 17.8 & 47030 & 35.9 & 2193 & 32778 & 74 \\
13 & 19.9 & 75610 & 31.8 & 503 & 35064 & 47 \\
14 & 20.5 & 60760 & 42.7 & 663 & 26503 & 45 \\
\hline
\end{tabular}

\section{Mycotoxin residues in serum}

The metabolite de-epoxy DON was detected in all serum samples of the cows in the mycotoxin period. The presence of de-epoxy DON was confirmed by HPLC-MS (Razzazi-Fazeli et al. 2003). Values ranged between 4 and $28 \mathrm{ngml}^{-1}$ (Figure 2). DON concentrations were all below the detection limit. DON could not be detected in the serum samples of the control period, whereas the concentrations of deepoxy DON ranged between below the detection limit and $5 \mathrm{ngml}^{-1}$. Furthermore, based on the analysis of six samples with and without incubation with $\beta$ glucuronidase, the degree of glucuronidation of de-epoxy DON was found to be $100 \%$. It has to be stressed, however, that it is possible that due to the low concentrations of conjugated de-epoxy DON in the serum samples, a slight amount of non-conjugated de-epoxy DON could not be detected.

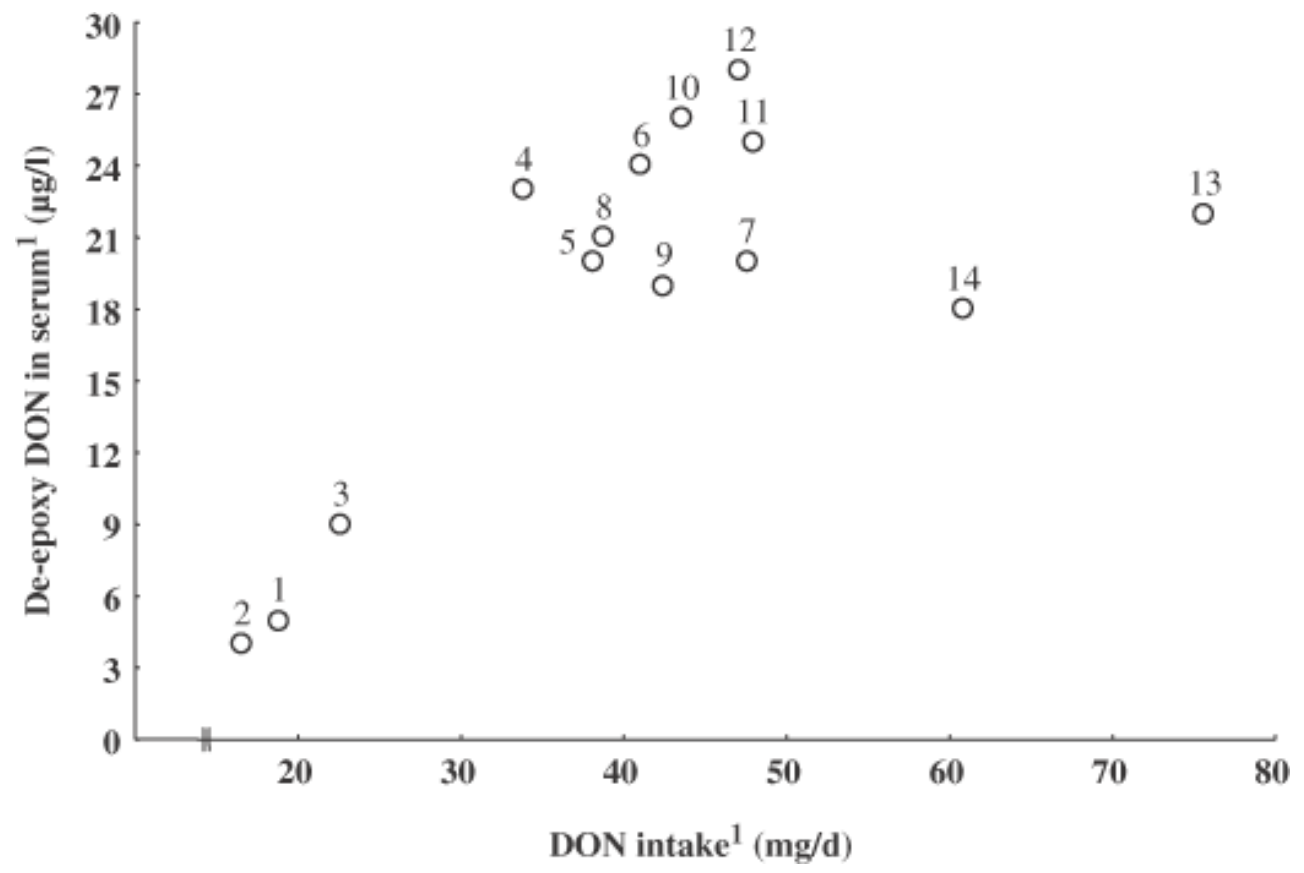

Figure 2. Relationship between deoxynivalenol (DON) intake $\left(\mathrm{mgday}^{-1}\right)$ and deepoxy DON residues in the serum of dairy cows in the mycotoxin period. Numbers over the symbols denote the individual cows. ${ }^{1}$ Measured by a high-performance liquid chromatography (HPLC) method. 


\section{Mycotoxin residues in milk}

Using the HPLC-UV method without $\beta$-glucuronidase incubation, de-epoxy DON was determined in only one sample (Table IV), whereas the metabolite was detected in the milk of all cows fed the contaminated wheat using the same method with $\beta$-glucuronidase incubation. Based on the analysis of the one sample, the degree of glucuronidation of de-epoxy DON was found to be approximately $77 \%$. DON was both with and without enzyme incubation in all milk samples below the indicated detection limit using the HPLC-UV method. Concentrations of de-epoxy DON in milk of cows fed the Fusarium toxincontaminated wheat ranged from 1.6 to $2.7 \mu \mathrm{gkg}^{-1}$ (HPLC-UV method with $\beta$ glucuronidase incubation).

Table IV. Deoxynivalenol (DON) and de-epoxy DON concentrations $\left(\mu \mathrm{gkg}^{-1}\right)$ in the milk of individual lactating cows in the mycotoxin period determined with a high-performance liquid chromatography-ultraviolet light (HPLC-UV) and a gas chromatography-mass spectrometry (GC-MS) method with and without $\beta$-glucuronidase incubation.

\begin{tabular}{|c|c|c|c|c|c|c|c|c|}
\hline & \multicolumn{4}{|c|}{ HPLC-UV ${ }^{1}$} & \multicolumn{4}{|c|}{ GC-MS ${ }^{2}$} \\
\hline & \multicolumn{2}{|c|}{$\begin{array}{l}\text { With } \beta \text { - } \\
\text { glucuronidase } \\
\text { incubation }\end{array}$} & \multicolumn{2}{|c|}{$\begin{array}{l}\text { Without } \beta- \\
\text { glucuronidase } \\
\text { incubation }\end{array}$} & \multicolumn{2}{|c|}{$\begin{array}{l}\text { With } \beta- \\
\text { glucuronidase } \\
\text { incubation }\end{array}$} & \multicolumn{2}{|c|}{$\begin{array}{l}\text { Without } \beta \text { - } \\
\text { glucuronidase } \\
\text { incubation }\end{array}$} \\
\hline Cow & DON & $\begin{array}{l}\text { De- } \\
\text { epoxy } \\
\text { DON }\end{array}$ & DON & $\begin{array}{l}\text { De- } \\
\text { epoxy } \\
\text { DON }\end{array}$ & DON & $\begin{array}{l}\text { De- } \\
\text { epoxy } \\
\text { DON }\end{array}$ & DON & $\begin{array}{l}\text { De- } \\
\text { epoxy } \\
\text { DON }\end{array}$ \\
\hline \multicolumn{9}{|c|}{ *Cows did not lactate. } \\
\hline \multicolumn{9}{|c|}{${ }^{1}$ Measured by an HPLC method (detection limit $=0.5 \mu \mathrm{gkg}^{-1}$ ). } \\
\hline \multicolumn{9}{|c|}{${ }^{2}$ Measured by a GC-MS method (detection limit $=0.1 \mu \mathrm{gkg}^{-1}$ ). } \\
\hline 1 & $-*$ & $-*$ & $-*$ & $-*$ & $-*$ & $-*$ & $-*$ & $-*$ \\
\hline 2 & $-*$ & $-*$ & $-*$ & $-*$ & $-*$ & $-*$ & $-*$ & $-*$ \\
\hline 3 & $-*$ & $-*$ & $-*$ & $-*$ & $-*$ & $-*$ & $-*$ & $-*$ \\
\hline 4 & $<0.5$ & 1.6 & $<0.5$ & $<0.5$ & 0.11 & 1.8 & $<0.1$ & 0.2 \\
\hline 5 & $<0.5$ & 1.6 & $<0.5$ & $<0.5$ & 0.13 & 1.7 & $<0.1$ & 0.3 \\
\hline 6 & $<0.5$ & 2.1 & $<0.5$ & $<0.5$ & 0.13 & 2.1 & $<0.1$ & 0.2 \\
\hline 7 & $<0.5$ & 1.2 & $<0.5$ & $<0.5$ & 0.15 & 1.5 & 0.10 & 0.2 \\
\hline 8 & $<0.5$ & 1.7 & $<0.5$ & $<0.5$ & 0.15 & 2.1 & $<0.1$ & 0.2 \\
\hline 9 & $<0.5$ & 1.6 & $<0.5$ & $<0.5$ & 0.15 & 2.2 & $<0.1$ & 0.4 \\
\hline 10 & $<0.5$ & 2.7 & $<0.5$ & 0.6 & 0.22 & 2.9 & 0.13 & 0.6 \\
\hline 11 & $<0.5$ & 1.8 & $<0.5$ & $<0.5$ & 0.22 & 3.1 & $<0.1$ & 0.3 \\
\hline 12 & $<0.5$ & 1.5 & $<0.5$ & $<0.5$ & 0.23 & 1.5 & 0.14 & 0.4 \\
\hline 13 & $<0.5$ & 1.5 & $<0.5$ & $<0.5$ & 0.26 & 2.7 & 0.11 & 0.5 \\
\hline 14 & $<0.5$ & 0.8 & $<0.5$ & $<0.5$ & 0.22 & 2.0 & 0.11 & 0.3 \\
\hline
\end{tabular}


Both DON and de-epoxy DON were detected using the more sensitive GC-MS method without and with enzyme incubation (Table IV). However, it has to be stressed that DON levels were barely above the detectable limit. Values of the further analysed trichothecenes in the milk were all below the detection limit. Concentrations of DON and de-epoxy DON in the milk of the cows fed the Fusarium toxin-contaminated wheat ranged between 0.1 and 0.3 and between 1.5 and $3.1 \mathrm{\mu g} \mathrm{kg}^{-1}$, respectively (GC-MS method with enzyme incubation; Table IV). The degree of glucuronidation of DON and de-epoxy DON was found to be between 33 and $62 \%$ and between 73 and $92 \%$, respectively. Based on the daily average weights of milk produced (Table III), the calculated daily excretion of DON and de-epoxy DON in milk of the cows fed the contaminated wheat ranged from $10 \mu \mathrm{gday}^{-1}$ and between 14 and $104 \mu \mathrm{gday}^{-1}$, respectively. The daily amounts of DON and de-epoxy DON in the milk increased significantly with increasing DON intake $\left(y=-4.512+2.098 e^{-4 * *} \bullet x, r^{2}=0.548, * * p<0.01\right.$ (DON), $y=-21.956+0.002 * \bullet x, r^{2}=0.407, * p<0.05$ (de-epoxy DON)). The total carry-over rates of ingested DON as DON and de-epoxy DON into milk ranged between 0.0001 and 0.0002 and between 0.0004 and 0.0024 , respectively, and did not correlate with the DON intake, as determined in the intake range $33.8-75.6 \mathrm{mg}$ DON per cow day ${ }^{-1}$. The total carry-over rates of ingested DON as DON and deepoxy DON are significantly linearly correlated with the milk yield (Figure 3 ). The daily flows of DON and de-epoxy DON at the duodenum are significant linearly correlated with the DON and de-epoxy DON amount in the milk (Figure 4). The duodenal carry-over rates of DON and de-epoxy DON into the milk ranged from 0.013 and between 0.0003 and 0.0007 . The daily milk yield did not correlate with the duodenal carry-over rates of DON and de-epoxy DON. The de-epoxy DON concentrations analysed with the GC-MS method were found to be to $0.13 \%$ higher as the results obtained with the HPLC-UV method.
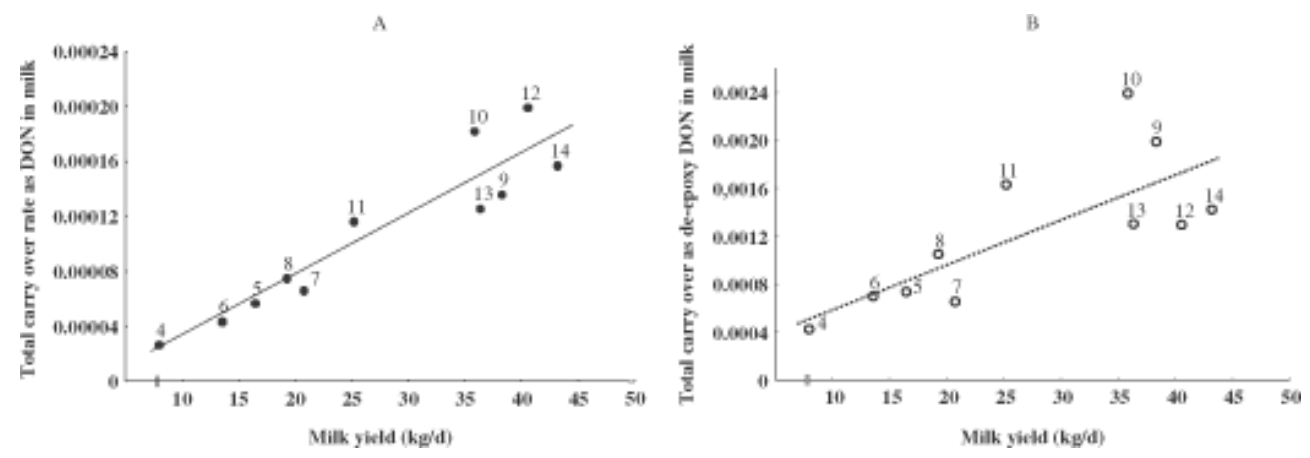

Figure 3. Relationship between milk yield $\left(\mathrm{kgday}^{-1}\right)$ and total carry-over rate of deoxynivalenol (DON) as DON (A) and de-epoxy DON (B) into milk of dairy cows in the mycotoxin period. $\bullet$, DON, $y=-1.277 e^{-5}+4.429 e^{-6 * * *} \bullet x, r^{2}=0.873$, $* * * p<0.001$; and $\hat{x}$, de-epoxy DON, $y=-2.31 e^{-4}+3.709 e^{-5 * *} \bullet x, r^{2}=0.559$, $* * p<0.01$. Numbers over the symbols denote the individual cows. 

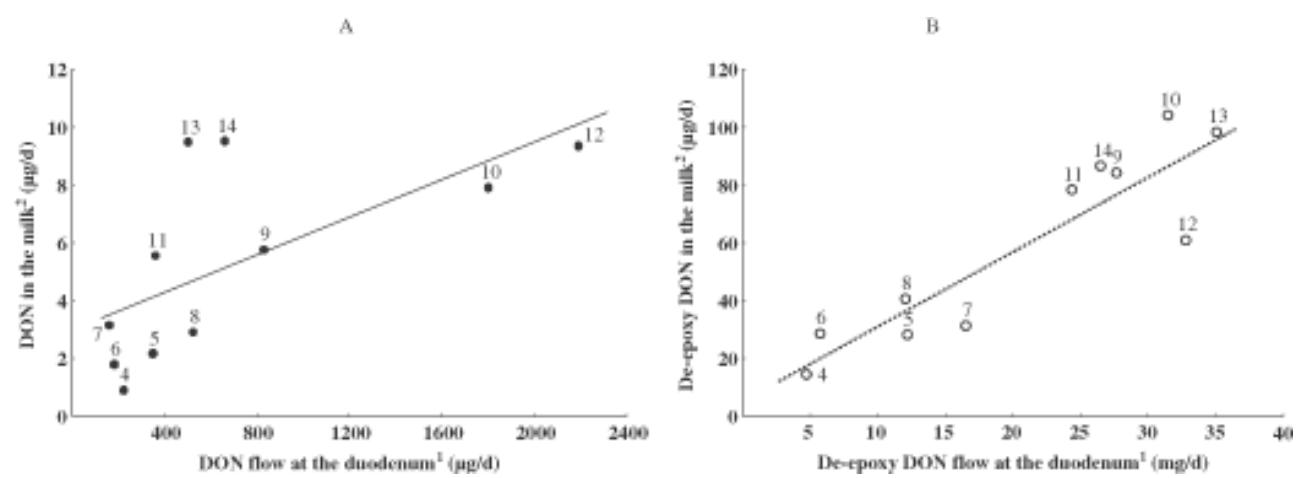

Figure 4. Relationship between deoxynivalenol (DON) and de-epoxy DON flow at the duodenum and DON (A) and de-epoxy DON (B) excretion in milk $\left(\mu\right.$ gday $\left.^{-1}\right)$ of dairy cows in the mycotoxin period. $\bullet$, DON, $y=3.038+0.003 * \cdot x, r^{2}=0.417$, $* p<0.05$; and $\hat{x}$, de-epoxy DON, $y=4.623+0.003 * * * \cdot x, r^{2}=0.814, * * * p<0.001$. Numbers over the symbols denote the individual cows. ${ }^{1}$ Measured by a highperformance liquid chromatography (HPLC) method with $\beta$-glucuronidase incubation. ${ }^{2}$ Measured by a gas chromatography-mass spectrometry (GC-MS) method with $\beta$-glucuronidase incubation.

DON and de-epoxy DON could not be detected in the milk samples of the control period.

\section{Mycotoxin excretion in urine and faeces}

DON and de-epoxy DON were detected in both urine and faeces of the cows in the control as well as in the mycotoxin period. Values of DON and de-epoxy DON in urine samples of the mycotoxin period ranged between 0.1 and $0.3 \mu \mathrm{gml}^{-1}$ and between 1.1 and $4.0 \mu \mathrm{gml}^{-1}$, respectively (Figure 5 ), whereas values in the control period were in the range below the detection limit and $0.2 \mu \mathrm{gml}^{-1}$ and between 0.1 and $0.4 \mathrm{gmml}^{-1}$, respectively. The portion of DON and de-epoxy DON of total DON plus de-epoxy DON concentration in urine in the mycotoxin period varied between 4 and $18 \%$ and between $82 \%$ and $96 \%$, respectively. Based on the analysis of six samples with and without incubation with $\beta$-glucuronidase, the degree of glucuronidation of DON and de-epoxy DON in urine samples was found to be between 21 and $92 \%$ and between 86 and $100 \%$, respectively. Daily DON and de-epoxy DON excretion in faeces of cows ranged between 89 and $1526 \mu \mathrm{g}$ and between 256 and $3978 \mu \mathrm{g}$ in the mycotoxin period, whereas values in the control period varied between 4 and $232 \mu \mathrm{g}$ and between 74 and $586 \mu \mathrm{g}$ (Figure $6)$, respectively. Thereby, the portions of DON and de-epoxy DON of DON intake were between 0.4 and $8.7 \%$ and between 1.2 and $16.9 \%$ when the Fusarium toxin-contaminated wheat was fed between 0.2 and $11.1 \%$ and between 3.1 and $18.5 \%$ feeding the control wheat, respectively. The total residues of DON plus deepoxy DON in faeces ranged between 2 and $18 \%$ and between 8 and $27 \%$ of DON intake in the mycotoxin and control period, respectively. DON and de-epoxy DON accounted for between 5 and $44 \%$ and between 56 and $95 \%$ of the residues of both substances in faeces when feeding the contaminated wheat and for 2-74\% and $27-98 \%$ of the residues of both substances in faeces when feeding the control wheat, respectively. 


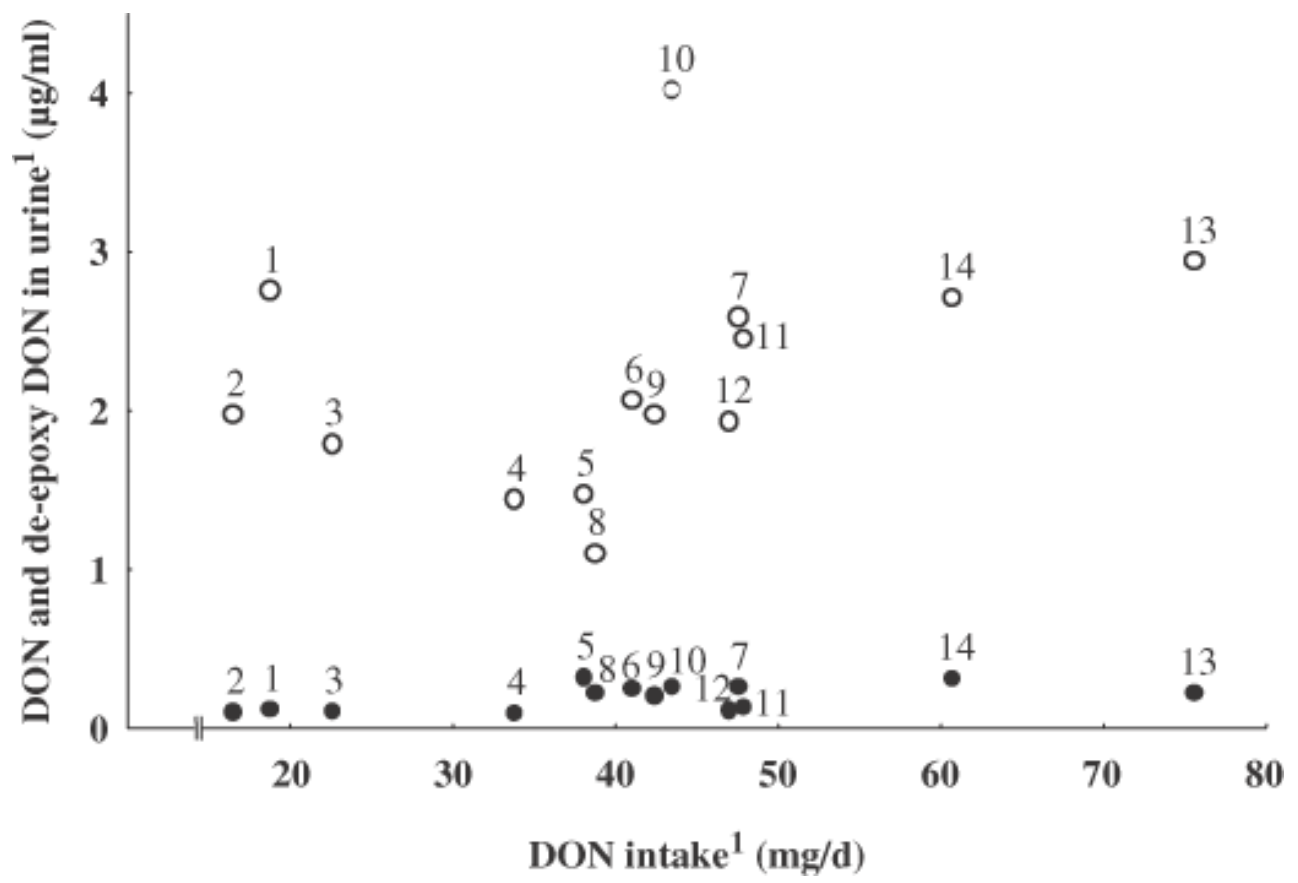

Figure 5. Relationship between deoxynivalenol (DON) intake and DON and deepoxy DON residues in urine of dairy cows in the mycotoxin period. $\bullet$, DON; and $\hat{x}$ , de-epoxy DON. Numbers over the symbols denote the individual cows. ${ }^{1}$ Measured by a high-performance liquid chromatography (HPLC) method.

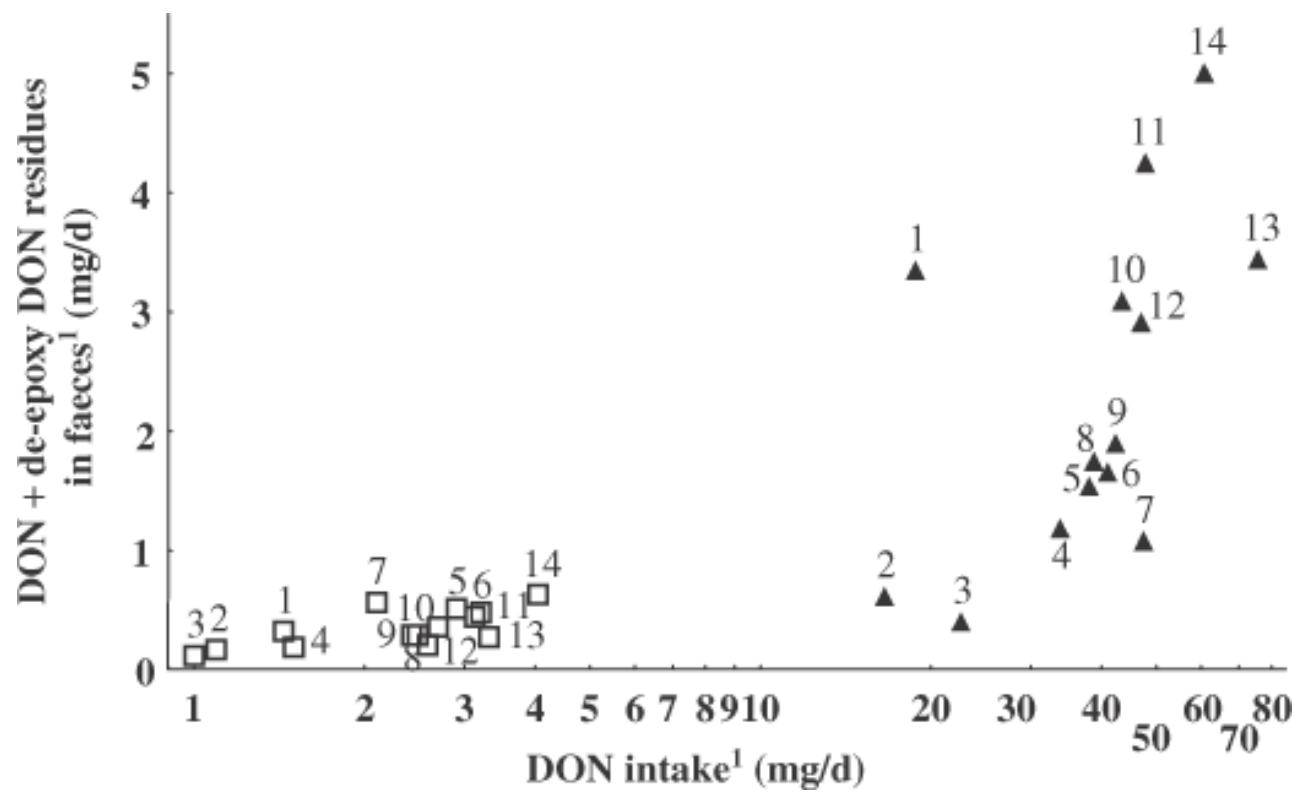

Figure 6. Relationship between deoxynivalenol (DON) intake and DON plus deepoxy DON residues in faeces of dairy cows in the mycotoxin period and control period. $\square$, Control period; and $\boldsymbol{\Delta}$, mycotoxin period. Numbers over the symbols denote the individual cows. ${ }^{1}$ Measured by a high-performance liquid chromatography (HPLC) method. 
Food Additives and Contaminants, Vol. 23, No. 10, October 2006, pp. 1008-1020

\section{Discussion}

Contradictory results have been obtained regarding the effects of DON on feed intake of ruminants. For example, Noller et al. (1979) found a slight decrease of daily feed intake with a concomitant decrease of body weight when feeding Gibberella zeae-infected corn in complete mixed rations to lactating dairy cows. Similarly, Trenholm et al. (1985) noticed that feed intake was slightly reduced when naturally contaminated grain (DON concentration to $6.4 \mathrm{mgkg}^{-1}$ ) was added to the ration of non-lactating cows. In contrast, the feeding of diets containing DON concentrations of 6 or $12 \mathrm{mgkg}^{-1}$ (Charmley et al. 1993) and to $14 \mathrm{mgkg}^{-1}$ concentrate (Ingalls 1996) did not affect the feed intake. In the present study, the average DON concentrations of the daily rations were 3.4 and $0.3 \mathrm{mgkg}^{-1}$ (at a reference dry matter content of $88 \%$ ) in the mycotoxin and control period, so that the critical DON concentration of $5 \mathrm{mg}$ per $\mathrm{kg}$ of the total daily ration at a reference dry matter content of $88 \%$ as issued for dairy cows by the German Ministry of Consumer Protection, Food and Agriculture (BML 2000) was not exceeded. With regard to the feed intake, the change in feeding the control wheat to feeding the Fusarium-contaminated wheat did not show any distinctive features.

Due to the detoxifying ability of the rumen microflora, ruminants appear to have a higher tolerance towards harmful substances such as DON. Several in vitro studies using bovine rumen fluid have shown that the toxin is de-epoxidized to the less toxic metabolite de-epoxy DON (King et al. 1984; Swanson et al. 1987; He et al. 1992). However, it is possible that a modified toxin profile could alter the toxicity possibly responsible for the variable effects observed when DON was fed to ruminants in practically relevant concentrations. Therefore, the present study was conducted to evaluate whether the feed intake, as an indicator for the feed retention in the rumen, could alter the metabolization and, therefore, the proportion of DON and de-epoxy DON reaching the duodenum and eventually the milk.

In the present experiment, the proportion of DON and de-epoxy DON at the duodenum relative to the DON intake varied between 12 and $77 \%$ when the Fusarium-contaminated wheat was fed (Table III) and between 32 and 153\% when the control wheat was fed. The higher recovery of DON and de-epoxy DON at the duodenum in the control period is possibly related to a higher variation coefficient of analytical results which is often found at lower DON concentrations (Whitaker et al. 2000). In the mycotoxin period, the recovery of DON and deepoxy DON as a percentage of DON intake was relatively constant at a low level $(12-23 \%)$ at the lower feed/DON intakes, while an increased level of feed/DON intake resulted in higher differences and recoveries (35-77\%). Furthermore, DON was almost completely biotransformed to de-epoxy DON, whereby the de-epoxy DON portion of the duodenal flow of both substances amounted to $99 \%$ in the mycotoxin period (Figure 1) and to $97 \%$ in the control period. Likewise, Dänicke et al. (2005), who fed fistulated dairy cows with Fusarium-contaminated wheat ( 8.05 and $7.15 \mathrm{mg} \mathrm{DON} \mathrm{kg}{ }^{-1}$ wheat dry matter) over a 35day period, found that $89 \%$ of the duodenal flow of both toxins was de-epoxy DON. Furthermore, 4$28 \%$ of ingested DON were recovered at the duodenum in the form of DON and de-epoxy DON at total daily dry matter intakes between 4 and $12 \mathrm{~kg}$, which corresponds well with the recovery rates of $12-35 \%$ obtained at daily dry matter intakes between 6 and $12 \mathrm{~kg}$ in the present study. The slightly higher recovery rates of $12-35 \%$ compared with $4-28 \%$ might possibly be caused by differences of diet composition because, in contrast to the present experiment, the wheat portion of the daily ration amounted to $50 \%$ (on a dry matter basis) in the study of Dänicke et al. (2005), and rations were completed by hay or grass silage. Dänicke et al. suggested that the low recovery of DON as the sum of DON and de-epoxy DON at the duodenum would indicate either a complete degradation of 
Food Additives and Contaminants, Vol. 23, No. 10, October 2006, pp. 1008-1020

the toxin in the rumen or an absorption by mucosa of the rumen. This presumption is supported by Prelusky et al. (1985) who calculated from the areas under the plasma-time concentration curves a mean pharmacokinetic bioavailability rate of $7.5 \%$ following administration of a single oral dose of $5 \mathrm{mg}$

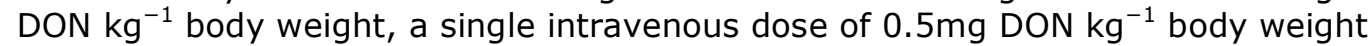
to sheep. Furthermore, along with the oral dose, a cobalt-ethylenediamine tetraacetic acid (EDTA) marker, which indicates the liquid phase, was added in the rumen. Due to the intensive disappearance rate of DON from the rumen which was two to three times faster than the marker, the authors also suggested a complete degradation and/or absorption of DON from the rumen. However, conversion of DON to de-epoxy DON in the rumen was found to occur only in $15 \%$ (Prelusky et al. 1985). In the present study and in the experiment by Dänicke et al. (2005), a high proportion of the flow of DON and de-epoxy DON at the duodenum was the metabolite de-epoxy DON (up to 99 and 89\%). Due to the low variation of the proportion of de-epoxy DON to DON of total DON plus deepoxy DON flow at the duodenum between the different DON/feed intakes in the current experiment, it can be concluded that DON is very rapidly biotransformed to de-epoxy DON. Moreover, the lower biological recovery of DON plus de-epoxy DON at the lower DON/feed intakes could possibly indicate a complete degradation of the toxin due to a higher ruminal retention time. Furthermore, deepoxy DON was the major component detected in the serum samples of cows fed the contaminated wheat in the present study, while concentrations of DON were all below the indicated detection limit (Figure 2). Moreover, the substance was only found as glucuronide conjugate, which implied that the toxin will go directly to the liver where it undergoes an extensive glucuronidation in the first-pass.

In contrast, Sabater Vilar (2003) found a mean DON content of $32 \mu \mathrm{gl}^{-1}$ using an ELISA method in blood serum of cows belonging to a Dutch farm. However, no data were given by the authors regarding the applicability of the applied ELISA method for determination of DON in serum. The authors supposed that the rumen was not able to degrade the amount of DON to which the animals were exposed. The estimated individual daily DON intake was $4.5 \mathrm{mg}$ at an average daily dry matter intake of $20 \mathrm{~kg}$, which is similar to the concentration of $0.3 \mathrm{mg}$ DON $\mathrm{kg}^{-1} \mathrm{dry}$ matter control diet in the present study. However, in the current experiment only trace amounts of de-epoxy DON were detected in the serum of the cows fed the control wheat, whereas concentrations of DON were in all samples below the detection limit. Accordingly, Prelusky et al. (1987) indicated that following an intravenous or a large single oral dose of DON, only a small fraction was present in the blood plasma as de-epoxy DON (Prelusky et al. 1984, $1985,1990)$. However a more prolonged oral exposure to a DON contaminated diet (330 and $880 \mathrm{mgkg}^{-1}$ diet) for 3days resulted in higher amounts of de-epoxy DON in the plasma. The authors supposed an efficient biotransformation of DON due to an extended exposure of DON to the rumen microflora. A similar pattern of DON and de-epoxy DON was observed in the serum and in the milk samples obtained from the present study. De-epoxy DON was detected as the predominant substance in the milk of cows fed the contaminated wheat mainly occurring as glucuronide conjugate (Figure 1 and Table IV). However, trace amounts of DON were detected beside the metabolite de-epoxy DON with the GCMS method (Table IV), although it needs to be stressed that the detected DON levels were barely above the detection limit. In general, knowledge about the carry-over of DON and de-epoxy DON into the milk of dairy cows is still deficient. While Charmley et al. (1993) reported no transmission of DON and de-epoxy DON in the milk of cows with a daily DON intake of $104 \mathrm{mg}$ (conjugated DON and deepoxy DON were not analysed), Prelusky et al. (1987) found maximum total DON residue levels of 222 and $135 \mathrm{ngml}^{-1}$, predominately as conjugated de-epoxy DON in milk of sheep fed extremely high oral doses of 4.0 and $1.5 \mathrm{~g}$ pure DON over a $72 \mathrm{~h}$ period. Only very low amounts of free and conjugated DON $\left(<4 \mathrm{ngml}^{-1}\right)$ were 
detected in the milk following a large single oral dose of $1.7 \mathrm{mg} \mathrm{DON} \mathrm{kg}^{-1}$ body weight to lactating dairy cows (de-epoxy DON was not analysed; Prelusky et al. 1984). Based on the levels of milk production, the carry-over rate of DON into the milk was almost negligible, only about $0.0001 \%$ of the administered dose. In the present experiment the total carry-over rate of DON as DON and de-epoxy DON transmitted into milk ranged between 0.0001 and 0.0002 and between 0.0004 and 0.0024 (GC-MS with enzyme incubation; Table IV). The results indicate a large difference in carry-over especially of de-epoxy DON between animals with lower and higher milk yields. For the mycotoxin aflatoxin $M_{1}\left(A F M_{1}\right.$, a metabolite of aflatoxin $B_{1}$ ), it is supposed that there is a passive concentration-dependent permeability of $\mathrm{AFM}_{1}$ from blood to the alveolar cells of the mammary gland (Veldman et al. 1992). Possibly such a concentration-dependent permeability exists for DON and de-epoxy DON, which could explain the significantly increasing total carry-over results of ingested DON as DON and de-epoxy DON in relation to the increased milk production. In addition, different permeabilities of the alveolar cell membranes might be responsible for the variation in de-epoxy DON carryover. Furthermore, Veldman et al. (1992) assumed that udder condition could also influence the carry-over of $\mathrm{AFM}_{1}$ because udder infections can increase the permeability of the udder. Therefore, increased udder permeability at the higher milk yields could also be a reason for the higher DON and de-epoxy DON contents in the milk. Further factors that could influence the DON and de-epoxy DON levels in milk might be equilibration between blood and other compartments, DON biotransformation, entero-hepatic circulation, rates of urinary and faecal elimination, and rates of absorption from different areas of the gastrointestinal tract (Prelusky et al. 1984). In the present study, the daily DON and de-epoxy DON flows at the duodenum are significantly linearly correlated with the daily DON and de-epoxy DON amounts in the milk (Figure 4).

DON and de-epoxy DON residues were also analysed in urine and faeces samples. In the current study, de-epoxy DON was compared with DON, the predominant substance in urine (Figure 5), which was supposed to be the most important excretion route in a study by Cote et al. (1986). The portion of deepoxy DON of the total DON plus de-epoxy DON concentration in urine amounted to $96 \%$ when the Fusarium toxin-contaminated wheat was fed. Furthermore, DON as well as de-epoxy DON residues in urine appeared mainly as glucuronide conjugate (66 and 98\%), which implied that glucuronic acid conjugation appears to be an important metabolic pathway. However, although all animals were in a steady feeding state, the urine concentrations of the present study should not be overvalued because samples were collected spontaneously without consideration of water intake and the kinetic behaviour of DON. Yet, the analyses show that DON and de-epoxy DON were also detected in the urine of the cows fed the control wheat with lower concentrations of DON in the diet. Prelusky et al. (1986) found that only $7 \%$ of DON and metabolites were eliminated with the urine and $55-75 \%$ of the DON dose appeared as unconjugated forms of DON and de-epoxy DON in the faeces. However, the assumption that DON seems to be excreted principally via the faeces cannot be confirmed by the present data. Only from 2 to $18 \%$ of consumed DON were excreted as DON plus de-epoxy DON in faeces when the Fusarium-contaminated wheat was fed. The method of DON administration possibly influences the urinary and faecal excretion rates of DON and de-epoxy DON because in contrast to the current experiment, Prelusky et al. (1986) administered a large single oral dose of DON at a level of $5 \mathrm{mgkg}^{-1}$ body weight Furthermore, for the present experiment, it has to be stressed that the faeces samples were also taken spontaneously without consideration of the kinetic behaviour of DON. However, all animals were in a steady feeding state and the daily amount of faeces from the cows was estimated using $\mathrm{Cr}_{2} \mathrm{O}_{3}$ as a marker. 


\section{Conclusion}

It can be concluded from this experiment that after the feeding of DONcontaminated diets (approximately $3.4 \mathrm{mg}$ DON and $0.3 \mathrm{mg} \mathrm{DON} \mathrm{kg}{ }^{-1}$ complete ration, at a reference dry matter content of $88 \%$, in the mycotoxin and control period) to dairy cows, DON is very rapidly biotransformed to de-epoxy DON in the rumen due to the low variation of the portion of de-epoxy DON of the total flow of DON plus de-epoxy DON at the duodenum between the different DON/feed intakes. Moreover, the lower biological recovery of DON plus de-epoxy DON at the duodenum at lower DON/feed intakes could possibly indicate a complete degradation of the toxin due to a higher ruminal retention time. Furthermore, excretion of DON and de-epoxy DON occurred through both urinary and faecal routes, with the urinary route seemingly the most important. Although very little amounts of DON and de-epoxy DON were transmitted into the milk of mycotoxinfed animals, the increasing carry-over rates of DON and de-epoxy DON with an increasing milk yield need to be examined further.

\section{References}

[1] Bassler, R (1976) Die chemische Untersuchung von Futtermitteln, Methodenbuch. Bd. 3 mit Ergänzungslieferungen 1983, 1988 and 1993 , editor. Darmstadt: VDLUFA.

[2] Bauer, ] (2000) Mykotoxine in Futtermitteln: Einfluss auf Gesundheit und Leistung, Handbuch der tierischen Veredlung. 25 , pp. 169-192. Auflage, Kammlage: Osnabrück.

[3] BML (The German Ministry of Consumer Protection, Food and Agriculture) (2000) Orientation values for critical concentrations of deoxynivalenol and zearalenone in diets for pigs, ruminants and gallinaceous poultry. VDM 27/00: 2-3 .

[4] Bottalico, A and Perrone, G (2002) Toxigenic Fusarium species and mycotoxins associated with head blight in small-grain cereals in Europe, European Journal of Plant Pathology, 108, pp. 611624.

[5] Charmley, E, Trenholm, HL, Thompson, BK, Vudathala, D, Nicholson, JWG, Prelusky, DB and Charmley, LL (1993) Influence of level of deoxynivalenol in the diet of dairy cows on feed intake, milk production and its composition, Journal of Dairy Science, 76, pp. 3580-3587.

[6] Cote, LM, Dahlem, AM, Yoshizawa, T, Swanson, SP and Buck, WB (1986) Excretion of deoxynivalenol and its metabolites in milk, urine and faeces of lactating dairy cows, Journal of Dairy Science, 69, pp. 2416-2423.

[7] Dänicke, S, Matthäus, K, Lebzien, P, Valenta, H, Ueberschär, K-H and Flachowsky, G (2005) On the effects of Fusarium toxins on the fermentation and nutrient utilization in rumen of dairy cows, Journal of Animal Physiology and Animal Nutrition, 89, pp. 303-315.

[8] Dänicke, S, Valenta, H and Ueberschär, KH (2000) Risikoabschätzung und Vermeidungsstrategien bei der Fütterung, in: S Dänicke and E Oldenburg (Eds). Risikofaktoren für die Fusariumtoxinbildung in Futtermitteln und Vermeidungsstrategien bei der Futtermittelerzeugung und Fütterung, pp. 5-34. Landbauforschung Völkenrode, Sonderheft No. 216.

[9] He, P, Young, LG and Forsberg, C (1992) Microbial transformation of deoxynivalenol (vomitoxin), Applied and Environmental Microbiology , 58, pp. 3857-3863.

[10] Höltershinken, M, Maiworm, K and Scholz, H (1996) Mykotoxikosen beim Rind - Probleme auch in Norddeutschland? Collegium Veterinaria , 26, pp. 9-14.

[11] Ingalls, JR (1996) Influence of deoxynivalenol on feed consumption by dairy cows, Animal Feed Science and Technology, 60, pp. 297-300.

[12] King, RR, McQueen, RE, Levesque, D and Greenhalgh, R (1984) Transformation of deoxynivalenol (vomitoxin) by rumen microorganisms, Journal of Agricultural and Food Chemistry, 32, pp. 11811183.

[13] Noller, CH, Stob, M and Tuite, J (1979) Effects of feeding Gibberella zeae-infected corn on feed intake, body weight gain and milk production of dairy cows, Journal of Dairy Science, 62, pp. 1003-1006.

[14] Oldenburg, E, Valenta, H and Sator, C (2000) Risikoabschätzung und Vermeidungsstrategien bei der Futtermittelerzeugung, in: S Dänicke and E Oldenburg (Eds). Risikofaktoren für die Fusariumtoxinbildung in Futtermitteln und Vermeidungsstrategien bei der Futtermittelerzeugung und Fütterung, pp. 5-34. Landbauforschung Völkenrode, Sonderheft No. 216.

[15] Prelusky, DB, Hartin, KE and Trenholm, HL (1990) Distribution of deoxynivalenol in cerebral spinal fluid following administration to swine and sheep, Journal of Environmental Science and Health $B$, 25, pp. 395-413. 
[16] Prelusky, DB, Trenholm, HL, Lawrence, GA and Scott, PM (1984) Transmission of deoxynivalenol (vomitoxin) to milk following oral administration to dairy cows, Journal of Environmental Science and Health B , 19, pp. 593-609.

[17] Prelusky, DB, Veira, DM and Trenholm, HL (1985) Plasma pharmacokinetics of the mycotoxin deoxynivalenol following oral and intravenous administration to sheep, Journal of Environmental Science and Health B , 20, pp. 603-624.

[18] Prelusky, DB, Veira, DM, Trenholm, HL and Foster, BC (1987) Metabolic-fate and elimination in milk, urine and bile of deoxynivalenol following administration to lactating sheep, Journal of Environmental Science and Health B , 22, pp. 125-148.

[19] Prelusky, DB, Veira, DM, Trenholm, HL and Hartin, KE (1986) Excretion profiles of the mycotoxin deoxynivalenol, following oral and intravenous administration to lactating sheep, Fundamental and Applied Toxicology, 6, pp. 356-363.

[20] Razzazi-Fazeli, E, Böhm, J, Jarukamjorn, K and Zentek, J (2003) Simultaneous determination of major B-trichothecenes and the de-epoxy-metabolite of deoxynivalenol in pig urine and maize using high-performance liquid chromatography-mass spectrometry, Journal of Chromatography $B$, 796, pp. 21-33.

[21] Rohr, K, Brandt, M, Castrillo, O, Lebzien, P and Assmus, G (1979) Der Einfluss eines teilweise Ersatzes von Futterprotein durch Harnstoff auf den Stickstoff- und Aminosäurenfluss am Duodenum, Landbauforschung Völkenrode , 29, pp. 32-40.

[22] Rohr, K, Brandt, M, Lebzien, P and Schafft, H (1984) Measurement of duodenal flow in dairy cows by either total collection or spot sampling, using a special cannula, Canadian Journal of Animal Science , 64(Suppl.), pp. 116-117.

[23] Rotter, BA and Prelusky, DB (1996) Toxicology of deoxynivalenol, Toxicology of Environmental and Health, 48, pp. 1-34.

[24] Sabater Vilar, M (2003) Assessment and intervention of food-and feed-borne mycotoxicoses [PhD thesis]. Utrecht: Department of Veterinary Pharmacology, Pharmacy and Toxicology, Utrecht University.

[25] Schollenberger, M, Müller, H-M, Rüfle, M, Suchy, S, Planck, S and Drochner, W (2005) Survey of Fusarium toxins in foodstuffs of plant origin marketed in Germany, International Journal of Food Microbiology, 97, pp. 317-326.

[26] Schothorst, RC, Jekel, AA, Van Egmond, HP, Van Klaveren, J, Boon, P and Tjoe Nij, EIM (2005) Determination of trichothecenes in duplicate diets for young children by capillary gas chromatography with mass spectrometric detection, Food Additives and Contaminants , 22, pp. 48-55.

[27] Seeling, K and Dänicke, S (2005) Relevance of the Fusarium toxins deoxynivalenol and zearalenone in ruminant nutrition: A review, Journal of Animal and Feed Science, 14, pp. 3-40

[28] Seeling, K, Dänicke, S, Ueberschär, KH, Lebzien, P and Flachowsky, G (2005) On the effects of a Fusarium toxin-contaminated wheat and the feed intake level on metabolism and carry over of zearalenone in dairy cows, Food Additives and Contaminants, 22, pp. 847-855.

[29] Seeling, K, Lebzien, P, Dänicke, S, Spilke, J, Südekum, KH and Flachowsky, G (2006) Effect of level of feed intake and of Fusarium toxin-contaminated wheat on rumen fermentation as well as blood and milk parameters in cows, Journal of Animal Physiology and Animal Nutrition, 90, pp. 103-115.

[30] StatSoft (1994) Statistica for the Windows ${ }^{\mathrm{TM}}$ Operating System . Tulsa, OK: StatSoft, Inc.

[31] Swanson, SP, Nicoletti, J, Rood, HD, Buck, WB, Cote, LM and Yoshizawa, T (1987) Metabolism of three trichothecene mycotoxins, T-2 toxin, diacetoxyscirpenol and deoxynivalenol, by bovine rumen microorganisms, Journal of Chromatography , 414, pp. 335-342.

[32] Trenholm, HL, Thompson, BK, Hartin, KE, Greenhalgh, R and McAllister, HJ (1985) Ingestion of vomitoxin (deoxynivalenol)-contaminated wheat by nonlactating dairy cows, Journal of Dairy Science , 68, pp. 1000-1005.

[33] Ueberschär, KH (1999) Einfluß von Zearalenon auf Wachstum und Rückstände in den Geweben von Mastkaninchen, VDLUFA-Kongreßband 1999, Halle/Saale, VDLUFA-Schriftenreihe, 52/1999, pp. 425-428.

[34] Valenta, H, Dänicke, S and Döll, S (2003) Determination of deoxynivalenol and de-epoxy deoxynivalenol in animal tissues by liquid chromatography after cleanup with an immunoaffinity column, Mycotoxin Research , 19, pp. 51-55.

[35] Valenta, H, Dänicke, S and Wolff, J (2002) Vergleich einer HPLC- und einer ELISA-Methode zur Bestimmung von Deoxynivalenol in Mühlenstäuben, Kleien und Getreide, VDLUFA-Kongressband 2002, VDLUFA-Schriftenreihe , 58, pp. 675-679.

[36] Veldman, A, Meijs, JAC, Borggreve, G] and Heeres-van der Tol, JJ (1992) Carry-over of aflatoxin from cows food to milk, Animal Production , 55, pp. 163-168. 
Food Additives and Contaminants, Vol. 23, No. 10, October 2006, pp. 1008-1020

[37] Whitaker, TB, Hagler, WM, Giesbrecht, FG and Johansson, AS (2000) Sampling, sample preparation and analytical variability associated with testing wheat for deoxynivalenol, Journal of AOAC International , 83, pp. 1285-1292.

[38] Whitlow, LW and Hagler, WM An association of mycotoxins with production, health and reproduction in dairy cattle and guidelines for prevention and treatment, in: TP Lyons and KA Jaques (Eds). Proceedings of Alltechs 15th Annual Symposium. Nottingham: Nottingham University Press, 1999, pp. 401-419.

[39] Williams, CH, Daivid, DJ and Iismaa, O (1962) The determination of chromic oxide in faeces samples by atomic absorption spectrophotometry, Journal of Agricultural Sciences, 59 ,pp. 381-385. 